\title{
INTRACELLULAR IDENTIFICATION OF CENTRAL NORADRENERGIC AND SEROTONERGIC NEURONS BY A NEW DOUBLE LABELING PROCEDURE ${ }^{1}$
}

\author{
G. K. AGHAJANIAN ${ }^{2}$ AND C. P. VANDERMAELEN \\ Departments of Psychiatry and Pharmacology, Yale University School of Medicine, Connecticut Mental Health Center,
} New Haven, Connecticut 06508

Received May 24, 1981; Accepted July 27, 1982

\begin{abstract}
The purpose of this study was to ascertain the identity of presumed noradrenergic or serotonergic neurons recorded by single cell techniques in the mammalian brain. A double labeling method was developed in which intracellular injections of a red fluorescing dye (ethidium bromide) could be colocalized with the formaldehyde-induced green fluorescence of norepinephrine or yellow fluorescence of serotonin. By this method, neurons of the rat locus coeruleus that display a characteristic activation-inhibition response to noxious stimuli were confirmed to be noradrenergic; the slow, rhythmically firing neurons of the dorsal raphe nucleus were confirmed to be serotonergic.
\end{abstract}

Noradrenergic and serotonergic neurons in the mammalian brain have been identified presumptively in single cell recording studies on the basis of anatomical location and certain distinguishing electrophysiological and pharmacological properties. For example, histochemical studies show a clustering of noradrenergic neurons in the locus coeruleus (Dahlström and Fuxe, 1965; Grzanna and Molliver, 1980) and serotonergic neurons in the dorsal raphe nucleus (Dahlström and Fuxe, 1965; Steinbush, 1981). Extracellular recordings from neurons within the locus coeruleus have revealed a homogeneous population of tonically firing cells that are inhibited by opiates (Bird and Kuhar, 1977; Korf et al., 1974) and $\alpha_{2}$-adrenoceptor agonists (Cedarbaum and Aghajanian, 1977; Svensson et al., 1975) and activated by noxious stimuli applied anywhere on the body (Cedarbaum and Aghajanian, 1978; Korf et al., 1974; Nakamura, 1977). Furthermore, locus coeruleus cells can be activated antidromically by electrical stimulation of the ascending noradrenergic (dorsal) fiber bundle (Aghajanian et al., 1977; Faiers and Mogenson, 1976; German and Fetz, 1976; Nakamura and Iwama, 1975). Presumed noradrenergic neurons of the locus coeruleus undergo a pronounced postactivation inhibition following either orthodromic (Cedarbaum and Aghajanian, 1978) or antidromic (Aghajanian et al., 1977) stimulation. Intracellular recordings from locus coeruleus

\footnotetext{
${ }^{1}$ We thank L. Fields, N. Margiotta, and A. Zimnewicz for their valuable assistance in this work. This research was supported by Public Health Service Grants MH-17871, MH-14459, and MH-14276 and the State of Connecticut.

${ }^{2}$ To whom correspondence should be addressed at Department of Psychiatry, Yale University School of Medicine, 34 Park Street, New Haven, CT 06508.
}

neurons have demonstrated similar postactivation inhibitions which are associated with large afterhyperpolarizations (Aghajanian and VanderMaelen, 1982a). Extracellular recordings from neurons within the dorsal raphe nucleus reveal a distinctive population of cells exhibiting a slow, regular firing pattern (Aghajanian et al., 1968; Bramwell, 1974; Mosko and Jacobs, 1974) and a characteristic set of other physiological and pharmacological properties (e.g., inhibition by $d$-lysergic acid diethylamide) which has led to their presumptive identification as serotonergic (for review, cf., Aghajanian, 1981). More recently, intracellular recordings have shown that pacemaker-like potentials underlie the slow, rhythmic firing pattern of presumed serotonergic neurons of the dorsal raphe nucleus (Aghajanian and VanderMaelen, 1982b).

Although much circumstantial evidence has now accumulated, there has not been any direct histochemical identification of single recorded noradrenergic or serotonergic neurons. In the present study, intracellular injections of ethidium bromide (an intensely red fluorescing dye) were made into presumptively identified noradrenergic neurons of the locus coeruleus and serotonergic neurons of the dorsal raphe nucleus; the brains then were processed by the Falck-Hillarp method for the histochemical demonstration of monoamines (Falck et al., 1962). As a control, cells of the mesencephalic nucleus of the trigeminal nerve (n. V), which do not contain monoamines, also were labeled. This technique allowed for a determination of whether there was a co-localization of ethidium bromide with norepinephrine or serotonin in the dye-injected cells. Ethidium bromide has been demonstrated to be useful for counterstaining immunofluorescent sections (Schmued et al., 1981) but has not been 
used previously for the intracellular marking of single neurons.

\section{Materials and Methods}

The experimental animals were male albino rats (Charles River) weighing 275 to $325 \mathrm{gm}$. For single cell recordings, the animals were anesthetized with chloral hydrate $(400 \mathrm{mg} / \mathrm{kg}$, i.p.) and mounted in a stereotaxic frame; body temperature was maintained at 35 to $37^{\circ} \mathrm{C}$. Micropipettes for recording and dye ejection were pulled from 2-mm glass tubing (Pyrex). The tubing had been preloaded with several filaments of fiberglass to promote filling by capillary action (Tasaki et al., 1968). The micropipettes were filled with a solution of potassium acetate $(1.0 \mathrm{M}, \mathrm{pH} 6.8)$ containing $1 \%$ ethidium bromide (Sigma). Electrodes then were beveled by the thick slurry method (Lederer et al., 1979) to a final impedance of 18 to 34 megohms. Because of the highly unstable recording conditions in both the locus coeruleus and dorsal raphe nucleus, four stabilizing pins (No. 0 Clay Adams insect pins) were set 1.5 to $2 \mathrm{~mm}$ apart in a square pattern in the brain around the recording site (cf., Aghajanian and VanderMaelen, 1982a, b). The pins served to reduce the local transmission of pulsations and other movements.

To obtain single cell recordings from locus coeruleus neurons, a burr hole was made $1.2 \mathrm{~mm}$ posterior to lambda and $1.1 \mathrm{~mm}$ lateral to the midline. As described previously (Aghajanian et al., 1977), practical aids in finding the locus coeruleus included: (1) a depth 5.5 to $6.5 \mathrm{~mm}$ below the brain surface; (2) a zone of relative electrical silence ventral to the cerebellum and dorsal to the locus coeruleus representing the fourth ventricle; (3) the presence just lateral to the locus coeruleus of cells of the mesencephalic nucleus of $\mathrm{n}$. V, which are activated by displacement of the mandible; and (4) in the locus coeruleus itself, a closely packed population of slowly firing cells ( 1 to 4 spikes/sec) all responding to noxious stimulation by a burst of firing allowed by a long quiescent period ( $\sim 1 \mathrm{sec})$.

For the dorsal raphe recordings, a midline burr hole was drilled 0.5 to $0.75 \mathrm{~mm}$ anterior to lambda. The dura (including the confluent sinus) was removed and bleeding was controlled with Gelfoam (Upjohn Co.). Typical dorsal raphe cells with a slow, regular firing pattern could be located in the region just ventral to the cerebral aqueduct; the latter could be identified readily as a zone of relative electrical silence. The ventral surface of the aqueduct was demarcated sharply by a sudden drop in DC potential (to approxiately $-80 \mathrm{mV}$ ) as ependymal cells were impaled 4.5 to $5 \mathrm{~mm}$ ventral to the brain surface.

Once cells of the locus coeruleus, the mesencephalic nucleus of $n$. V, or the dorsal raphe nucleus were identified tentatively by their extracellular firing characteristics, they were impaled either by inducing a brief period of "ringing" via the capacity compensator of a model M707 Microprobe System (W-P instruments, Inc.) or by a pulse of DC current (e.g., $20 \mathrm{~V}, 2 \mathrm{mS}$ ) applied through the recording electrode via a "breakaway box." If the impalements were stable for several minutes and showed membrane potentials $>30 \mathrm{mV}$, ethidium bromide, which is a basic dye (Lille, 1977), was ejected into cells by means of pulses $(1 \mathrm{~Hz}, 800 \mathrm{mS}$ ) of positive current (1 to
$2 \mathrm{nA}$ ) for a period of 1 to $2 \mathrm{~min}$. Preliminary experiments had shown that ejections of ethidium bromide at higher currents or for longer durations produced red fluorescent labeling of such high intensity that it interfered with the visualization of monoamine fluorescence. Two to 6 cells were labeled in each experimental animal; a stereotaxic map was constructed of the relative position of each of the labeled cells.

Tissues were prepared for fluorescence microscopy by a modification of the formaldehyde condensation method (Falck et al., 1962) for the demonstration of monoamines. In dorsal raphe labeling experiments, the animals were treated for $1 \mathrm{hr}$ prior to decapitation with the monoamine oxidase inhibitor pargyline $(100 \mathrm{mg} / \mathrm{kg}$, i.p.) and L-tryptophan $(100 \mathrm{mg} / \mathrm{kg}$, i.p.) to enhance selectively the histofluorescence of serotonergic neurons (Aghajanian and Asher, 1971). No pretreatment was given in the case of locus coeruleus labeling experiments. After completion of the intracellular injections, rats were guillotined, and their brains were removed rapidly. Coronal slices $(2 \mathrm{~mm}$ in thickness) of midbrain or anterior pons were cut, placed on Gelfoam strips, and immediately quenched in a mixture of propane and propylene (10:1) cooled by liquid nitrogen. The tissues then were placed in a desiccator over $\mathrm{P}_{2} \mathrm{O}_{5}$ and freeze-dried in a vacuum at $25^{\circ} \mathrm{C}$ for 3 to 4 days. The dried tissue then was exposed for $1.5 \mathrm{hr}$ to formaldehyde gas generated at $80^{\circ} \mathrm{C}$ from paraformaldehyde powder $(1 \mathrm{gm} / 100 \mathrm{ml}$ of chamber). The paraformaldehyde had been equilibrated previously with an atmosphere of $60 \%$ relative humidity. Tissues were vacuum-embedded in paraffin, and serial sections of the pons or midbrain were cut at $10 \mu \mathrm{m}$ and mounted on glass slides in nonfluorescent immersion oil. Slides were examined by means of a microscope (Zeiss Universal) equipped with a $200-\mathrm{W}$ mercury vapor lamp. The excitation filter (BG-12) had a peak transmission of $400 \mathrm{~nm}$. For visualizing monoamines, a barrier filter with a peak transmission of $500 \mathrm{~nm}$ was used in combination with another filter with a cutoff at $650 \mathrm{~nm}$ (to suppress red fluorescence). To visualize the ethidium bromide, the same excitation filter was used, but a switch was made to a barrier filter with a peak transmission of $590 \mathrm{~nm}$ (red pass). The ethidium bromide also could be activated selectively by an excitation filter with a peak transmission of $546 \mathrm{~nm}$; however, this was not useful for photography because of excessive light scattering even if the sections were deparaffinized. When cells labeled with ethidium bromide were located, microscopic fields were photographed (Tri-X-Pan, Kodak) with the monoamine barrier filter combination $(500-\mathrm{nm}$ peak transmission, $650-\mathrm{nm}$ cutoff) and then the same field was rephotographed using the red pass filter (590-nm transmission) for ethidium bromide. This sequence had the advantage of capturing the monoamine fluorescence prior to fading, which was particularly noticeable in the case of serotonin. No fading of ethidium bromide fluorescence was observed even with continued exposure to the activating light for periods up to several hours.

\section{Results}

Electrophysiological studies. As previously described, cells of the locus coeruleus could be identified tentatively by their characteristic activation by noxious stimulation 
(e.g., pinch of contralateral toe) followed by a postactivation inhibition (Fig. 1, top trace). As would be expected from previous intracellular studies (Aghajanian and VanderMaelen, 1982a), a prolonged afterhyperpolarization accompanied the postactivation inhibition. Cells of the mesencephalic nucleus of $n$. $V$, which were located just lateral to the locus coeruleus, showed a burst of spikes in response to mechanical displacement of the mandible (Fig. 1, middle trace). Mesencephalic n. V neurons were distinguished further from locus coeruleus neurons by their short duration action potentials $(<1 \mathrm{mS}$ versus $4 \mathrm{mS}$ for locus coeruleus neurons) and by the absence of a prolonged afterhypolarization.

In the dorsal raphe nucleus, the predominant type of

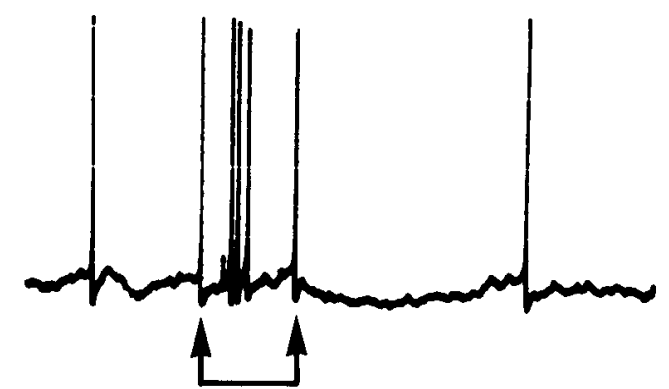

locus coeruleus
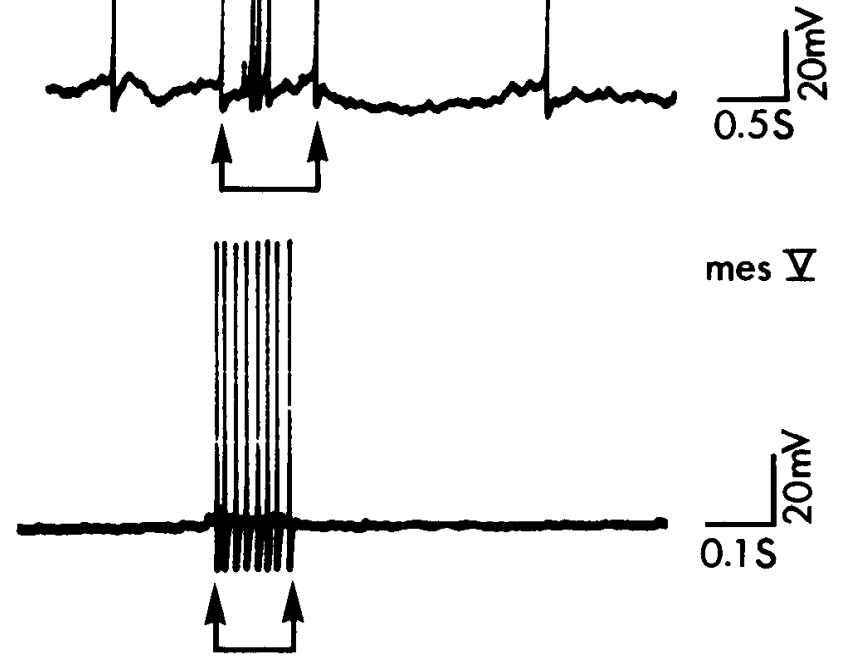

mes $\nabla$

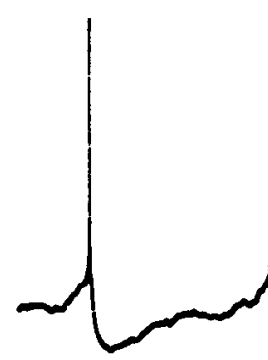

dorsal raphe

Figure 1. Intracellular recordings from the locus coeruleus, mesencephalic nucleus of the $n$. $V$, and the dorsal raphe nucleus showing the properties of typical neurons in these areas. In the top trace, a spontaneously firing locus coeruleus neurons is shown responding with a burst of spikes to a pinch of the contralateral toe (arrows); note the prolonged afterhyperpolarization and period of suppressed firing lasting approximately 3 sec. In the middle trace, a cell of the mesencephalic nucleus of n. V (mes $V$ ) in which a burst of spikes has been induced by a brief displacement of the mandible (arrows) is shown; note the lack of a persistent afterhyperpolarization. The bottom trace shows a typical dorsal raphe neuron exhibiting a slow, regular firing pattern with a pronounced hyperpolarization after each spike and a gradual interspike depolarization. Following the injection of ethidium bromide, the physiological properties of these cells were not altered. All traces were photographed on line from a storage oscilloscope. spontaneously active cells had a slow, rhythmic character as previously described. As illustrated in Figure 1 (bottom trace), such cells had large afterhyperpolarizations and gradual interspike depolarizations (cf., Aghajanian and VanderMaelen, 1982b). They also had long duration action potentials ( 3 to $4 \mathrm{mS}$ ) in contrast to other types of cells in the central gray or reticular formation.

Histochemical studies. A total of 15 locus coeruleus neurons were injected with ethidium bromide $(n=5$ animals); of these, 12 were recovered in tissue sections from brains processed by the Falck-Hillarp method (Falck et al., 1962). As can be seen from Figure 2 (left panel), when the monoamine filter combination was used, ethidium bromide-labeled cells could not be distinguished easily from other cells in the locus coeruleus since all exhibited bright norepinephrine-derived green fluorescence. However, when the red pass barrier filter was used, labeled cells had a brilliant red fluorescence which could be distinguished readily from other locus coeruleus cells; the latter fluoresced only weakly in the red portion of the spectrum. It should be noted, that ethidium bromide also stained the cell nucleus, including the nucleolus; this is evident in both panels of Figure 2 . In some of the same animals in which locus coeruleus cells were labeled, mesencephalic $n$. V cells also were labeled with ethidium bromide; of these, 10 out of 10 were recovered in the histological sections. As illustrated Figure 2 (left panel), injected mesencephalic $n$. V cells had only a faint red fluorescence when viewed with the monoamine filter combination. In contrast, when viewed with the red pass filter (Fig. 2, right panel), mesencephalic $n$. V cells exhibited a bright red fluorescence which surpassed that of all the locus coeruleus neurons except those labeled with ethidium bromide.

In the dorsal raphe nucleus, 20 slow, rhythmically firing cells were injected with ethidium bromide $(n=5$ animals). Of these, 15 were recovered in histological sections; all of the recovered cells also displayed yellow serotonin-derived fluorescence. Figure 3 (left panel) shows the ventral aspect of the dorsal raphe nucleus as seen with the monoamine barrier filter combination. Two cells (arrows) in this field had been labeled with ethidium bromide but, because of their yellow fluorescence, could not be distinguished from other cells in the nucleus which also exhibited a bright yellow, serotonin-derived histofluorescence. However, the ethidium bromide labeling became obvious when the red pass filter was used to examine the same field (Fig. 3, right panel).

\section{Discussion}

The results of this study show that intracellular injections of ethidium bromide can be combined with a standard histochemical procedure (i.e., the Falck-Hillarp method) to achieve reliably a double fluorescence labeling of noradrenergic and serotonergic neurons in the central nervous system. Neurons presumptively identified as noradrenergic according to previous criteria (e.g., location in locus coeruleus, responsiveness to noxious stimulation, prolonged postactivation inhibition, etc.) were double labeled invariably by this technique. In contrast, labeled neurons of the mesencephalic nucleus of $n$. V showed fluorescence due to ethidium bromide but 


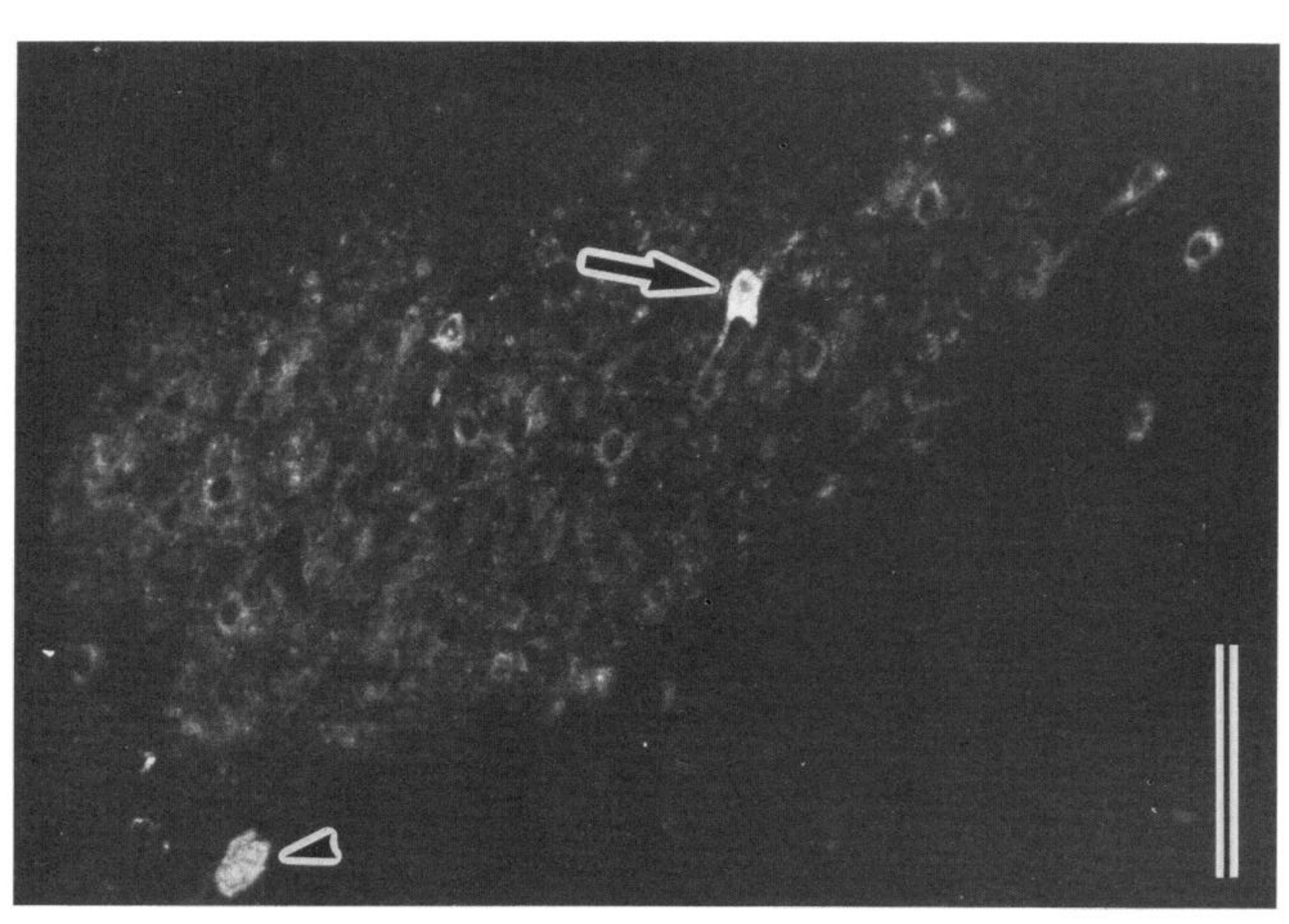

워요

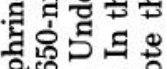
家

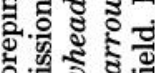
a

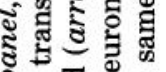
D. o.

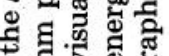
둥 运递 당 ¿ 영 용ㄱㅇㅛ

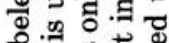

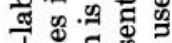

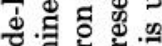
ีㅡㄹ 궁 范》正

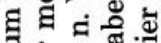
ํํํํำ 혀용

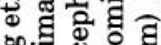
흐응 호 웡

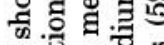

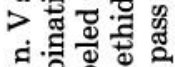
4ै

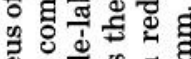
훙 者起

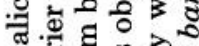
형

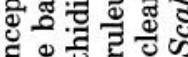
吉吉造 ฉี สี

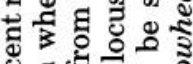
द

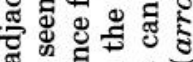

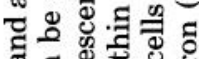
क्ष 을 월.

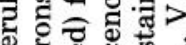

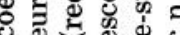
o

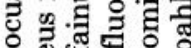
익 起 फ 역 육열

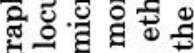

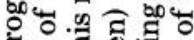

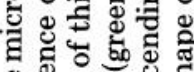
\& 过要 㻤 क्षे 는

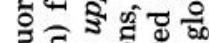

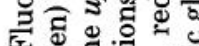
ง

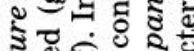
ऽ。广

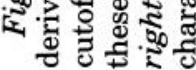




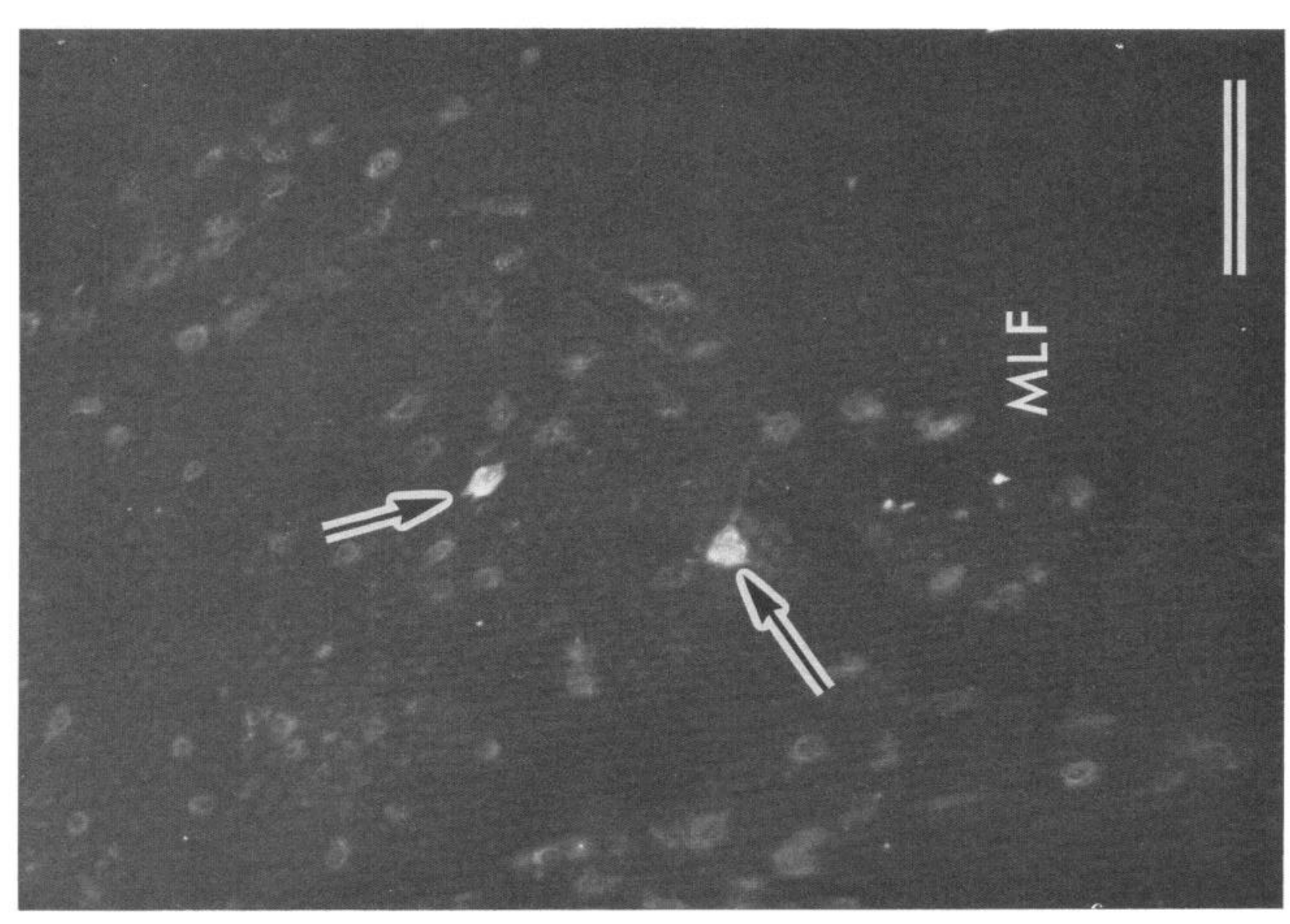

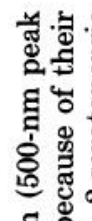

เี

שึ

롱

8 :

농

击

हึ ฮ

๘

궁

है

는

월.

3 .

\&

웡

过

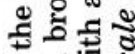

표

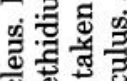

형

ฮี่

幽 สิ

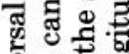

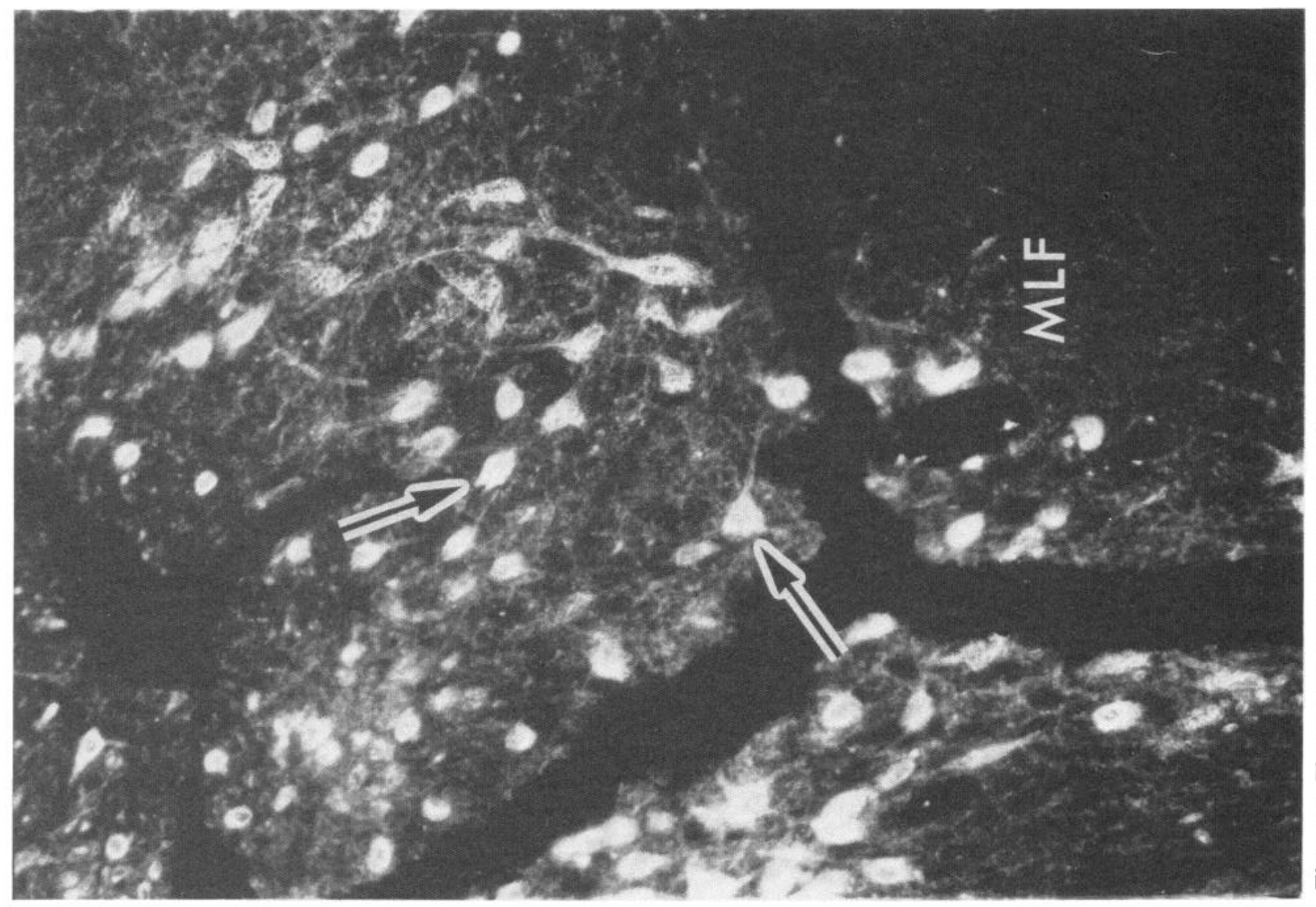

을 पㄷㅇㅇ

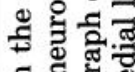

政

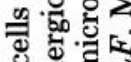

동

هั

क क :

웡

记

ह ․ㅇㅇ

อํํㄹ 워

国

च。

궁요 屯ै

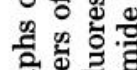

额产

응 중

घ웜

옥

르렬

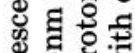

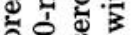

引웅 क

不

\%

员

敋 
no formaldehyde-induced monoamine fluorescence. Neurons presumptively identified as serotonergic on the basis of previous criteria (e.g., location in dorsal raphe nucleus, slow, rhythmic firing pattern, etc.) showed both formaldehyde-induced yellow fluorescence and red fluorescence due to the dye injection. Although non-serotonergic neurons are found in the dorsal raphe nucleus (Aghajanian et al., 1978), the present results suggest that the rhythmically firing cells in this nucleus are mainly, if not exclusively, serotonergic in nature. Of course, for purposes of demonstration, nuclei were chosen for study that are known to have a high density of noradrenergic or serotonergic neurons. In the future, it should be useful to apply the same double labeling technique to regions where the populations of neurons are less homogeneous and more difficult to identify.

Previous approaches to identifying central noradrenergic and serotonergic neurons in single cell recording experiments have had the disavantage of being either indirect or nonspecific. For example, previous intracellular studies in the locus coeruleus (Aghajanian and VanderMaelen, 1982a) and the dorsal raphe nucleus (Aghajanian and VanderMaelen, 1982b) have used horseradish peroxidase as an intracellular marker. However, because of the nonspecific nature of horseradish peroxidase, the histochemical identity of the cells could not be known with certainty. A more specific intracellular approach to identifying monoamine cells in the brain has been to inject $\mathbf{L}$-dopa (the immediate precursor of dopamine) into dopaminergic neurons of the substantia nigra to increase their aldehyde-induced fluorescence (Grace and Bunney, 1980). However, in preliminary experiments, we found that a similar precursor-loading method would not work well for noradrenergic or serotonergic neurons since the histofluorescence of cells was already generally bright in the locus coeruleus and quite variable in the dorsal raphe nucleus making judgments uncertain about the identity of injected cells. The present method has the advantage of using a marker (i.e., ethidium bromide) which emits a red fluorescence that is qualitatively different from any endogenous or aldehyde-induced fluorophores. Another advantage of ethidium bromide is the fact that it has a high quantum yield, allowing for the use of extremely low current intensities and short durations of ejection (e.g., 1 to $2 \mathrm{nA}, 1$ to $2 \mathrm{~min}$ ). In fact, at higher ejection currents, the ethidium bromide fluorescence was so great that it tended to obscure monoamine fluorescence. A further advantage of ethidium hromide is that it is inexpensive and readily available from commercial sources. Finally, because of its high solubility, ethidium bromide can be used in routine intracellular electrode solutions (e.g., in potassium acetate, as in the present study). Despite its high solubility, ethidium bromide is an excellent Nissl stain (Schmued et al., 1981) and does not elute from tissue sections during washing steps. Thus, we have been able to mark cells intracellularly with ethidium bromide for routine histology on standard frozen sections which then can be examined in the fluorescence microscope without further processing (G. K. Aghajanian and C. P. VanderMaelen, unpublished results).

\section{References}

Aghajanian, G. K. (1981) The modulatory role of serotonin at multiple receptors in brain. In Serotonin Neurotransmission and Behavior, B. L. Jacobs and A. Gelperin, eds., pp. 156185, MIT Press, Cambridge, MA

Aghajanian, G. K., and I. M. Asher (1971) Histochemical fluorescence of raphe neurons: Selective enhancement by tryptophan. Science 172: 1159-1161.

Aghajanian, G. K., and C. P. VanderMaelen (1982a) Alpha-2adrenoceptor mediated hyperpolarization of locus coeruleus neurons: Intracellular studies in vivo. Science 215: 1394-1396.

Aghajanian, G. K., and C. P. VanderMaelen (1982b) Intracellular recordings from serotonergic dorsal raphe neurons: Pacemaker potentials and the effect of LSD. Brain Res., 238: 463-469.

Aghajanian, G. K., W. E. Foote, and M. H. Sheard (1968) Lysergic acid diethylamide: Sensitive neuronal units in the midbrain. Science 161: 706-708.

Aghajanian, G. K., J. M. Cedarbaum, and R. Y. Wang (1977) Evidence for norepinephrine-mediated collateral inhibition of locus coeruleus neurons. Brain Res. 136: 570-577.

Aghajanian, G. K., R. Y. Wang, and J. M. Baraban (1978) Serotonergic and non-serotonergic neurons of the dorsal raphe: Reciprocal changes in firing induced by peripheral nerve stimulation. Brain Res. 153: 169-175.

Bird, S. J., and M. J. Kuhar (1977) Iontophoretic application of opiates to the locus coeruleus. Brain Res. 122: 523-533.

Bramwell, G. (1974) Factors affecting the activity of 5-HT containing neurons. Brain Res. 79: 515-519.

Cedarbaum, J. M., and G. K. Aghajanian (1977) Catecholamine receptors on locus coeruleus neurons: Pharmacological characterization. Eur. J. Pharmacol. 44: 375-385.

Cedarbaum, J. M., and G. K. Aghajanian (1978) Activation of locus coeruleus neurons by peripheral stimuli: Modulation by a collateral inhibitory mechanism. Life Sci. 23: 1383-1392.

Dahlström, A., and K. Fuxe (1965) Evidence for the existence of monoamine-containing neurons in the central nervous system. I. Demonstration of monoamines in the cell bodies of brainstem neurons. Acta Physiol. Scand. Suppl. 62 232: 1-55.

Faiers, A. A., and G. J. Mogenson (1976) Electrophysiological identification of neurons in locus coeruleus. Exp. Neurol. 53: 254-266.

Falck, B., N. A. Hillarp, G. Thieme, and A. Torp (1962) Fluorescence of catecholamines and related compounds condensed with formaldehyde. J. Histochem. Cytochem. 10: 348354.

German, D. C., and E. Fetz (1976) Responses of primate locus coeruleus and subcoeruleus neurons to stimulation at reinforcing brain sites and to natural reinforcers. Brain Res. 109: 497-515.

Grace, A. A., and B. S. Bunney (1980) Nigral dopamine neurons: Intracellular recording and identification with L-dopa injection and histofluorescence. Science 210: 654-656.

Grzanna, R., and M. E. Molliver (1980) The locus coeruleus in the rat: An immunohistochemical delineation. Neuroscience 5: $21-40$.

Korf, J., B. S. Bunney, and G. K. Aghajanian (1974) Noradrenergic neurons: Morphine inhibition of spontaneous activity. Eur. J. Pharmacol. 25: 165-169.

Lederer, W. J., A. J. Spindler, and D. A. Eisner (1979) Thick slurry bevelling: A new technique for bevelling extremely fine microelectrodes and micropipettes. Pfluegers Arch. 381: 287288.

Lillie, R. D., ed. (1977) H. J. Cohn's Biological Stains, William and Wilkins, Baltimore.

Mosko, S. S., and B. L. Jacobs (1974) Midbrain raphe neurons: 
Spontaneous activity and response to light. Physiol. Behav. 13: $589-593$.

Nakamura, S. (1977) Some electrophysiological properties of neurons of rat locus coeruleus. J. Physiol. (Lond.) 267: 641658.

Nakamura, S., and K. Iwama (1975) Antidromic activation of rat locus coeruleus neurons from hippocampus, cerebral and cerebellar cortices. Brain Res. 99: 372-376.

Schmued, L. C., L. W. Swanson, and P. E. Sawchenko (1981) Some fluorescent counterstains for neuroanatomical studies. Soc. Neurosci. Abstr. 7: 417.
Steinbush, H. W. M. (1981) Distribution of serotonin-immunoreactivity in the central nervous system of the rat-cell bodies and terminals. Neuroscience 6: 557-618.

Svensson, T. H., B. S. Bunney, and G. K. Aghajanian (1975) Inhibition of both noradrenergic and serotonergic neurons in brain by the alpha-adrenergic agonist, clonidine. Brain Res. 92: 291-306.

Tasaki, K., U. Tsukahara, S. Ito, M. J. Wayner, and W. Y. Yu (1968) A simple, direct and rapid method for filling microelectrodes. Physiol. Behav. 3: 1009-1010. 